\title{
THE EFFECT OF VIBRATION THERAPY ON REDUCTION OF MATRIX METALLOPROTEINASE-9 IN DIABETIC ULCER
}

\author{
Yunita Sari', Eman Sutrisna², Hartono³, Camila Quinetti Paes ${ }^{4}$ \\ 1Department of Nursing, Jenderal Soedirman University, Purwokerto, Indonesia \\ 2Department of Medical Science, Jenderal Soedirman University, Purwokerto, Indonesia \\ 3Department of Physics Science, Jenderal Soedirman University, Purwokerto, Indonesia \\ ${ }^{4}$ Integrated Technologies Laboratory, Federal University of Santa Catarina (UFSC), \\ Florianópolis, Brazil \\ Corresponding author : yunita-tky@umin.ac.jp/yunita.unsoed@gmail.com
}

\begin{abstract}
Background: One important reason why diabetic ulcer fails to heal is an increase of collagen degradation by matrix metalloproteinase-9 (MMP-9). Vibration therapy is one of complementary therapies which can reduce inflammation and improve reepithelialization. However, up to present, there is no study that investigate the effect of vibration on reduction of MMP-9 in diabetic ulcer. Therefore, the effect of vibration on reduction of collagen degradation in diabetic ulcer is still unknown. If vibration can reduce collagen degradation in diabetic ulcer, nurse can recommend patients to apply vibration not only during inflammation and proliferation phase, but also during maturation phase since MMP9 also contributes to collagen degradation during maturation phase.

Purpose: The purpose of this study was to investigate the effect of vibration on reduction of MMP-9 in diabetic ulcer.

Methods: Diabetic rats were divided into two groups, vibration and control groups. The intensity of polymorphonuclears cells (PMNs) and fibroblast, collagen appearance, and the presence of positive cells for MMP-9 were compared. Fibroblast, PMNs and collagen appearance were stained with $\mathrm{H}$ and $\mathrm{E}$ staining, and MMP-9 was stained by immunohistochemistry method. The difference in the intensity of fibroblast and PMNs was analyzed by Mann-Whitney $U$ test.

Results : The result showed that the intensity of PMNs was significantly lower, and the intensity of fibroblast was higher in vibration group than in control. Collagen alignment in the vibration group was more organized in a more regular fashion than in control group. The intensity of positive cells for MMP-9 was lower in the vibration group than in control group.

Conclusion : This study showed that vibration could reduce MMP-9, therefore it could be concluded that vibration could reduce collagen degradation of diabetic ulcer. This study bring implication in the clinical setting that vibration therapy should also be applied during maturation phase since MMP-9 is also released in the maturation phase.
\end{abstract}

Keyword : Complementer therapy, diabetic ulcer ; MMP-9; vibration therapy. 


\section{BACKGROUND}

Diabetes mellitus (DM) is a debilitating disease that causes increase of mortality and morbidity. The number of people living with DM in the world was 108 million in 1980, and became 422 million in 2014 (World Health Organization, 2016). It is estimated that the number will go even higher in the future. The prevalence of people with DM in Indonesia is also high and is estimated to increase. It is predicted that 2030 , there will be 12 million people with DM in Indonesia (Shaw, Sicree, \& Zimmet, 2010). Diabetes mellitus causes many complications. One of the most common chronic complications of DM is diabetic ulcer. Previous study in Eastern Indonesia showed that the prevalence of DM in Indonesia was $12 \%$ (Yusuf et al., 2016) This prevalence is high compared with a global prevalence of DM in the world.

Recently there is increase of number of wound care therapy such as a modern wound dressing that could be used in Indonesia. This modern wound dressing could accelerate wound healing of diabetic ulcer. However, diabetic ulcer which was accompanied by ischemia (mixed type/ ischemia and neuropathy) needs therapy that can improve blood flow.

One of complementary therapies that can improve the blood flow is vibration therapy (Maloney-Hinds, Jerrold Scott Petrofsky, 2008; Nakagami et al., 2007). Previous study revealed that vibration therapy could improve the increase of blood flow/angiogenesis of diabetic ulcer (Weinheimer-Haus, Judex, Ennis, \& Koh, 2014). Study by author revealed that vibration therapy, which was given in a low frequency could reduce inflammation and improve reepithelialization of diabetic ulcer (Sari,
Sutrisna, \& Hartono, 2016). The effect of vibration was even better than electrical stimulation, which was a device that also can improve blood flow in the wound (Sari, Saryono, Sutrisna, \& Hartono, 2017)

One of reasons of failure of healing in diabetic ulcer is the increase of collagen degradation by matrix metalloproteinases in the wound (Ayuk, Abrahamse, \& Houreld, 2016). Matrix metalloproteinases will catalyze the hydrolysis of collagen, elastin, laminin and fibronectin (Xue \& Jackson, 2015). Previous study showed that collagen degradation in diabetic ulcer was mainly done by matrix metalloproteinase- 9 (MMP-9) (Liu et al., 2009). In intact skin and acute wound, the MMP-9 expression is very low. Matrix metalloproteinase- 9 has an important role in wound healing during inflammation, proliferation and maturation phase. However, the level of MMP-9 will increase significantly in chronic wound such as diabetes compared with acute wound (Ulrich, Lichtenegger, Unglaub, Smeets, \& Pallua, 2005). The excessive of MMP-9 will impair wound healing since the new form collagen will be degraded by MMP9 (Liu et al., 2009). To accelerate the healing of diabetic ulcer, it is needed to reduce the level of MMP-9 in the diabetic ulcer. However, up to present, there is no study that investigates the effect of vibration therapy on reduction of MMP-9 in diabetic ulcer. If the effect of vibration on reduction of MMP-9 is known, it will bring a great implication in the clinical setting. Up to present, nurse usually applied vibration in the inflammation and proliferation of wound healing. However, MMP-9 is released and responsible for collagen degradation not only in inflammation and proliferation phase of wound healing, but also in maturation 
phase. If vibration can reduce MMP-9, we can recommend nurse to apply vibration not only during inflammation and proliferation phase of wound healing, but also in the maturation phase. The purpose of this study was to investigate the effect of vibration therapy on reduction of MMP-9 in diabetic ulcer.

\section{METODE}

The design of this study was an experimental study involving diabetic rats. The approach of the study was post test only with control group design. Male Wistar Rats which were purchased from Muhammadiyah Purwokerto University were used in this study. The rats were put in cage which has free access to water and food. The age of rats was 1314 weeks old. The study has been approved by research committee ethic, Faculty of Medicine, Jenderal Soedirman University.

Diabetic rats were divided into two groups. They were a vibration-treated group, and control group. The vibration group received vibration of $40 \mathrm{~Hz}$ for 10 minutes, starting on day 1 . The vibration was given once a day for 7 days, while the control group received only standard treatment. Standard treatment consists of dressing change daily by $\mathrm{NaCl} 0.9 \%$ and application of parafilm dressing to the wound site.

This study used a vibration device which was originally made by our research team (Sari et al., 2016). Briefly, the rat was anastesized during vibration. The rats were placed on the vibrating bed which its frequency could be changed according to protocols. The wound was placed directly attach to the vibrating bed. The vibration of $40 \mathrm{~Hz}$ for 10 minutes was applied to rat.

Induction of rats.
Alloxan monohydrate with a dose of 90 $\mathrm{mg} / \mathrm{Kg}$ body weight was used to induct rat become diabetic rats. Before and 4 days after injection, the blood glucose of rats were assessed. Rats were included in the sample if the blood glucose was $250 \mathrm{mg} / \mathrm{dl}$ or above. Before wounding, the hair of rat was shaved. Wounding procedure was conducted by using a knife, as described in the previous study (Sari, Saryono, Purnawan, \& Hartono, 2015). The diameter of wound was one centimeter, with a depth to panniculus carnosus. After wounding, the rats were given parafilm dressing, and fixated by gauze dressing. The dressing change was conducted daily for 8 days. The digital camera was used to record the wound appearance.

\section{Tissue staining}

The tissue sample was harvested on day 8. The tissue samples were placed in 10 $\%$ formalin, and undergone a series of tissue processing and finally embedded into paraffin. The section was then stained with Hematoxylin and Eosin staining, and then observed under microscope. For immunohistochemistry, the sections were placed on placed on poly-L-Lysine coated slides. Hydrogen peroxide $3 \%$ was used for reducing endogeneous peroxidase. Mouse monoclonal antibody MMP-9 was used. Diaminobenzidine was used as chromogen. The positive cells for MMP-9 was indicated by the color of bluish brown in fibroblast.

\section{Statistical Analysis}

The histological result for the intensity of PMNs and fibroblast was analyzed by Mann-Whitney U-tests. The value of $p<0,05$ was considered significant. The statistical analysis was conducted by using SPSS version of 16 . 


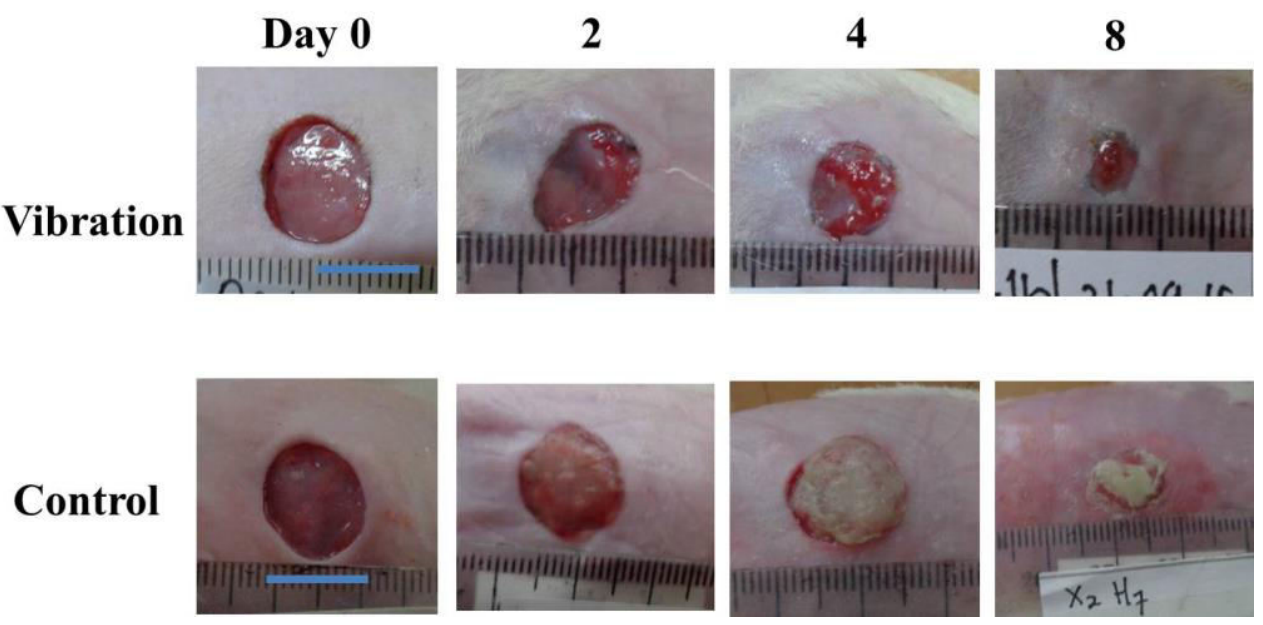

Figure 1. The visual difference of wound in the vibration and control group $(\mathrm{bar}=1 \mathrm{~cm})$
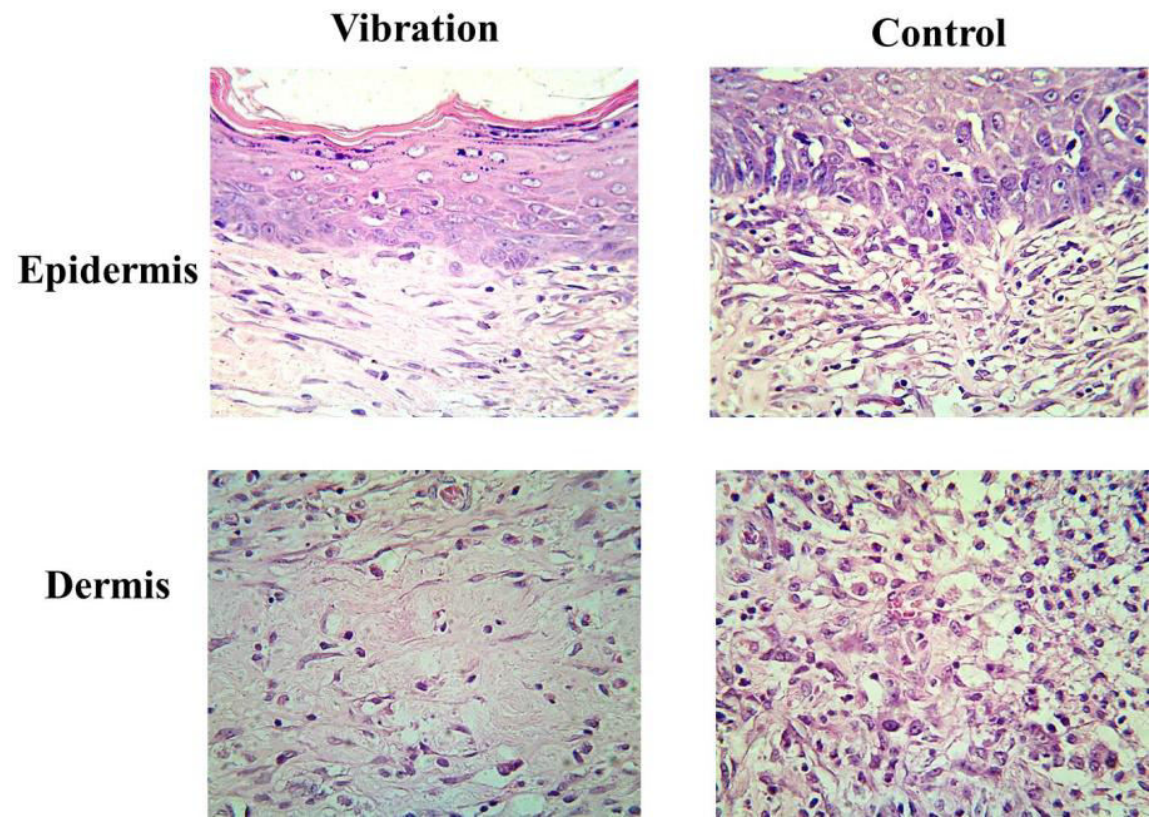

Figure 2. Hematoxilin and Eosyn staining between vibration group and control group in epidermis and dermis layer (magnification of 400 times)

\section{RESULT}

Macroscopical findings were shown in figure 1 . On day 0 , the depth of the wound in vibration and control groups were the same. The wound that reached panniculus carnosus could be seen in both groups. On day 2, there was no slough in vibration group, however, thin slough started to appear in the control group. On day 4, the wound base in the vibration group was filled with granulation tissue while in the control group was covered by a thick slough. On day 8 , the wound was almost closed by new epitel, however, in the control group, wound was still covered by slough. 
Tabel 1. The difference of the intensity of

inflammation and intensity of fibroblast

\begin{tabular}{|l|c|c|}
\hline Groups & PMNs & Fibroblas \\
\hline Vibration & $2^{*}$ & $4^{*}$ \\
\hline Control & 4 & 3 \\
\hline
\end{tabular}

Values indicated median score

Rating scale : $0=$ absent, $1=$ occasional, $2=$ moderate, $3=$ abundant, $4=$ very abundant ${ }^{*} P<0.05$

PMNs = polymorphonuclear neutrophils

The data of microscopical findings of vibration and control group in epidermis and dermis layers were shown in figure 2. It could be seen that collagen alignment in control group was an asymmetrically distributed, while the collagen alignement in the vibration group was more organized in a more regular fashion. The difference in the intensity of PMNs and intensity of fibroblast was shown in table 1. Table 1 showed that the intensity of inflammation was significanly lower in the vibration group $(P=0.026)$, and the intensity of fibroblast was significantly higher in the vibration compared with control group $(P=0.034)$.
The

result

of

immunohistochemistry in the upper part of dermis and lower part of dermis was shown in figure 3. Positive cells for MMP9 was indicated by the presence of brown colour that located in the cells. It could be seen that many MMP-9 positive cells located in the fibroblast cells, either in the upper dermis layer or in the lower part of dermis layer. Figure 3 showed that the intensity of MMP-9 positive cells in the upper part of dermis was lower in the vibration group compared with control group. Similarly, the intensity of MMP-9 positive cells in lower part of dermis was also lower compared with control group.

\section{DISCUSSION}

Our study is the first study that investigate the effect of vibration on reduction of MMP-9 in diabetic ulcer. This study showed that vibration could reduce MMP-9 in diabetic ulcer.

\section{Vibration}

\section{Upper part of dermis}

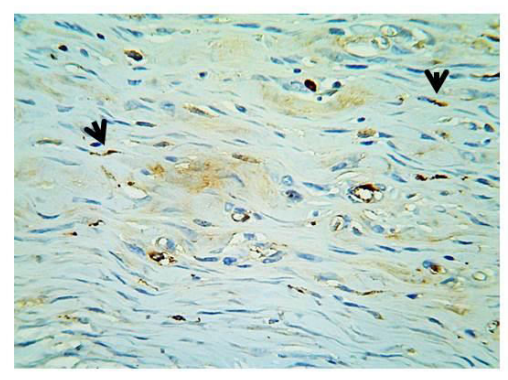

\section{Lower part of dermis}

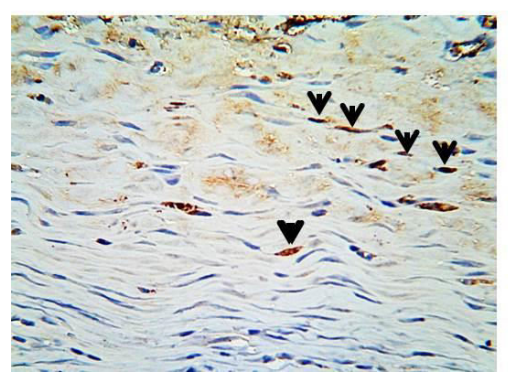

\section{Control}
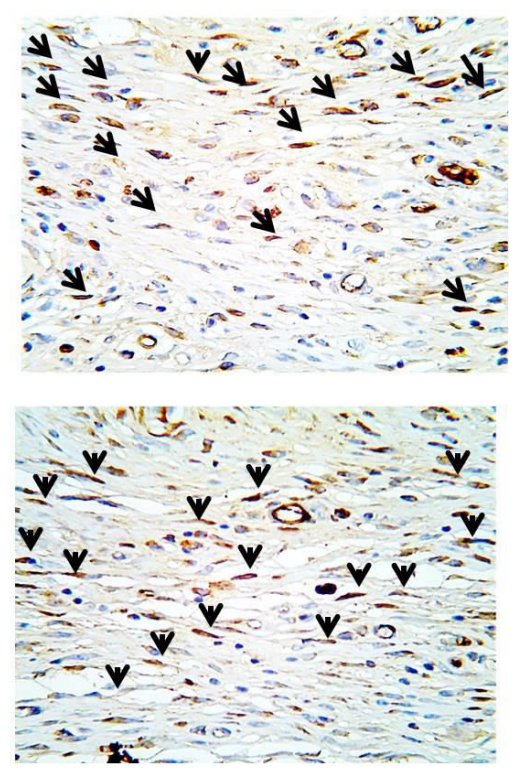

Figure 3. The MMP- 9 positive cells (arrow) between vibration and control in upper part of dermis (below epidermis) and lower part of dermis (Magnification of 400 times) 
Previous study showed that MMPs play an important role in wound healing. They are removal of damage extracellular matrix (ECM) and bacteria in inflammation phase, degradation of capillary basement membrane for angiogenesis and migration of epidermal cells during proliferation phase, and contraction of scar ECM and remodelling scar ECM during maturation phase (Gibson, Cullen, Legerstee, Harding, \& Schulz, 2009). However, if MMPs are present at wound bed at too high a level, it could degrade protein and finally impair wound healing (McCarty \& Percival, 2013). Previous study showed that MMP9 was increased in diabetic ulcer (Liu et al., 2009). The increase of MMP-9 will impair wound healing since it causes excessive collagen degradation (Liu et al., 2009). Our finding is in accordance with Liu et al (2009), the intensity of positive cells for MMP-9 in our study is also high in the diabetic rat. The high level of MMP-9 might cause excessive collagen degradation in the control group, resulted in slow wound healing as appear in the macroscopical findings.

The mechanism by which MMP9 level in diabetic ulcer is increased is still uncertain. Previous study showed that hypoxia and inflammation will cause an increase of MMP-9 (Catrina \& Zheng, 2016; Gibson et al., 2009). Inflammation can cause the increase of MMP-9 since the inflammatory cells like neutrophyl and macrophag can release MMP-9 (Gibson et al., 2009). In our study, the tissue hypoxia is not assessed, however previous study showed that tissue hypoxia is common to occur in diabetic ulcer since there is a lack of blood flow (Catrina \& Zheng, 2016). Therefore, We suggest that tissue hypoxia also occur in our diabetic rat model. Related with the increase of MMP-9 due to inflammation, our histological findings showed that the intensity of PMNs in the control group is higher than in vibration group. Therefore, we suggested that the increase of MMP9 in our study might due to hypoxia and inflammation.

Our research showed that vibration could reduce the intensity of positive cells of MMP-9. Previous study in pressure ulcer showed that vibration could reduce hypoxia condition, which resulted in a decrease of MMP-2 and MMP-9 (Sari, et al., 2015). Based on the previous study, it could be suggested that the decrease of the intensity of MMP-9 might due to the increase of blood flow, resulted in the decrease of hypoxia condition. Next study is needed to elucidate the mechanism of the decrease of MMP-9 following vibration.

In the previous studies, our study revealed that vibration could reduce inflammation and improve reepithelialization of diabetic ulcer (Sari et al., 2016). Therefore, vibration is needed to be used during inflammation and proliferation phase of wound healing. However, in this study, we found that vibration could also reduce MMP-9. MMP-9 will present in all phases of wound healing, not only in inflammation and proliferation phase, but also during maturation phase. The excessive of MMP-9 in the remodelling phase will cause impairment in the wound contraction and remodelling of scar. Based on this study, we suggest nurse should also apply vibration during maturation phase of wound healing, not only in the inflammation and proliferation phase of wound healing.

\section{CONCLUSION}

This study is the first study in the literature to investigate the effect of vibration on reduction 0 MMP-9 in 
diabetic ulcer. We showed that wound treated with vibration therapy has lower intensity of positive cells for MMP-9 compared with wound treated with standard wound care. Based on this study, it could be suggested that nurse should use vibration therapy not only in the inflammation and proliferation phase, but also during maturation phase of wound healing, since MMP-9 is also released in the maturation phase of wound healing. Future study in human subject is needed to confirm the effect of vibration on MMP-9 reduction in patient with diabetic ulcer.

\section{ACKNOWLEDGMENT}

This research has been funded by Competency research grant (third year). The authors would like to acknowledge ministry of research, technology and higher educaton who support this study through the research grant.

\section{REFERENCES}

Ayuk, S. M., Abrahamse, H., \& Houreld, N. N. (2016). The Role of Matrix Metalloproteinases in Diabetic Wound Healing in relation to Photobiomodulation. Journal of Diabetes Research, 2016. https://doi.org/10.1155/2016/28976 56

Catrina, S., \& Zheng, X. (2016). Disturbed hypoxic responses as a pathogenic mechanism of diabetic foot ulcers. Diabetes/Metabolism Research and Reviews, 32, 17985. https://doi.org/10.1002/dmrr

Gibson, D., Cullen, B., Legerstee, R., Harding, K. S., \& Schulz, G. (2009). MMPs made easy. Wounds International, 1(1), 1-6.

Liu, Y., Min, D., Bolton, T., Nube, V., Twigg, S. M., Yue, D. K., \&
McLennan, S. V. (2009). Increased Matrix Metalloproteinase-9 Predicts Poor Wound Healing in Diabetic. Diabetes Care, 32(1), 117-119. https://doi.org/10.2337/dc08-0763.

Maloney-Hinds, Jerrold Scott Petrofsky, G. Z. (2008). The effect of $30 \mathrm{~Hz}$ vs. $50 \mathrm{~Hz}$ passive vibration and duration of vibration on skin blood fl ow in the arm. Med Sci Monit, 14(3), 112-116. https://doi.org/836575 [pii]

McCarty, S. M., \& Percival, S. L. (2013). Proteases and Delayed Wound Healing. Advances in Wound Care, 2(8), 438-447. https://doi.org/10.1089/wound.2012 .0370

Nakagami, G., Sanada, H., Matsui, N., Kitagawa, A., Yokogawa, $H_{\text {., }}$ Sekiya, N., ... Shibata, M. (2007). Effect of vibration on skin blood flow in an in vivo microcirculatory model. BioScience Trends, 1(3), 161-166.

Sari, Y., Sanada, H., Minematsu, T., Nakagami, G., Nagase, T., Huang, L., ... Sugama, J. (2015). Vibration inhibits deterioration in rat deeptissue injury through HIF1-MMP axis. Wound Repair and Regeneration, 23(3), 386-393. https://doi.org/10.1111/wrr.12286

Sari, Y., Saryono, Purnawan, I., \& Hartono. (2015). Modifikasi Pompa ASI Sebagai Terapi Luka Bertekanan Negatif Untuk Mempercepat Penyembuhan Luka Diabetes, Jurnal ners, 10(1), 104111.

Sari, Y., Sutrisna, E., \& Hartono. (2016). Pengaruh Frekuensi Vibrasi terhadap Penyembuhan Luka Diabetes The Provision of Different Vibration Frequency to Accelerate Diabetic Wound Healing. Jurnal 
Keperawatan Padjajaran, 4, 117126.

Shaw, J. E., Sicree, R. A., \& Zimmet, P. Z. (2010). Global estimates of the prevalence of diabetes for 2010 and 2030. Diabetes Research and Clinical Practice, 87(1), 4-14. https://doi.org/10.1016/j.diabres.20

09.10 .007

Ulrich, D., Lichtenegger, F., Unglaub, F., Smeets, R., \& Pallua, N. (2005). Effect of Chronic Wound Exudates and MMP-2/-9 Inhibitor on Angiogenesis In Vitro. Plastic and Reconstructive Surgery, 116(2), 539-545.

https://doi.org/10.1097/01.prs.0000 173447.81513.7a

Weinheimer-Haus, E. M., Judex, S., Ennis, W. J., \& Koh, T. J. (2014). Low-intensity vibration improves angiogenesis and wound healing in diabetic mice. PLOS ONE, 9(3), 310.

https://doi.org/10.1371/journal.pone .0091355

World Health Organization. (2016). Global Report on Diabetes. Geneva: World Health Organization. Acessed in 25 May 2016. Available at http://apps.who.int/iris/bitstream/10 665/204871/1/9789241565257_eng .pdf

Xue, M., \& Jackson, C. J. (2015). Extracellular Matrix Reorganization During Wound Healing and Its Impact on Abnormal Scarring. Advances in Wound Care, 4(3), 119-136.

https://doi.org/10.1089/wound.2013 .0485

Yusuf, S., Okuwa, M., Irwan, M., Rassa, S., Laitung, B., Thalib, A., ... Sugama, J. (2016). Prevalence and Risk Factor of Diabetic Foot
Ulcers in a Regional Hospital, Eastern Indonesia. Open Journal of Nursing, 6(January), 1-10. https://doi.org/10.4236/ojn.2016.61 001 